\title{
The Severity of Anaemia in Primigravida in Rural Area of Krishna District
}

\author{
Dr. Pernenkil Srinivasa Rao ${ }^{1}$, Mahathi Bommaka ${ }^{2 *}$, Dr. Anusha $D^{3}$, Dr. Vijayalakshmi Udupi Badikillaya ${ }^{4}$ \\ ${ }^{1}$ Assistant Professor, Department of Physiology, Dr. Pinnamaneni Siddhartha Institute of Medical Sciences \& Research Foundation, Chinnautupalli, \\ Gannavaram, Andhra Pradesh, 521286, India \\ ${ }^{2}$ House Surgeon, Dr. Pinnamaneni Siddhartha Institute of Medical Sciences \& Research Foundation, Chinnautupalli, Gannavaram, Andhra Pradesh, \\ 521286, India \\ ${ }^{3}$ Assistant Professor, Department of Physiology, Dr. Pinnamaneni Siddhartha Institute of Medical Sciences \& Research Foundation, Chinnautupalli, \\ Gannavaram, Andhra Pradesh, 521286, India \\ ${ }^{4}$ Professor, Department of Biochemistry, NRI Academy of Medical Sciences, Mangalagiri Road, Chinakakani, Guntur, Andhra Pradesh, 522503, \\ India
}

DOI: $10.36348 /$ SIJAP.2019.v02i09.001

| Received: 19.08.2019 | Accepted: 26.08.2019 | Published: 11.09 .2019

*Corresponding author: Mahathi Bommaka

\section{Abstract}

Introduction: Anaemia in pregnancy remains one of the most intractable public health problems in the developing countries. World Health Organization has estimated that more than half of the pregnant women in the world are anemic. Anaemia during pregnancy is associated with adverse infant outcomes, including low birth weight, preterm delivery and perinatal mortality, and it may also be associated with childhood intellectual disability. Objective: To estimate the prevalence of anaemia in primigravida, classify the severity of anaemia in different age groups. Material \& Methods: It is a cross sectional study. Haemoglobin of 187 primigravida subjects in a tertiary hospital was estimated. The subjects were divided into age groups, below 20 years, 20- 25 years and more than 25 years. The mean and standard deviations of haemoglobin in different age groups were calculated. Observation \& Results: Out of 187 primigavida pregnant women $91.1 \%$ below 20 years, $77.77 \%$ from $20-25$ years and $36.58 \%$ of more than 25 years were anaemic. Their mean Hb was $9.89 \mathrm{gms} / 100 \mathrm{ml}, 9.9 \mathrm{gms} / 100 \mathrm{ml}$ and $11.1 \mathrm{gms} / 100 \mathrm{ml}$ respectively.

Keywords: Anaemia, haemoglobin, primigravida, pregnancy, rural area, Krishna district.

Copyright @ 2019: This is an open-access article distributed under the terms of the Creative Commons Attribution license which permits unrestricted use, distribution, and reproduction in any medium for non-commercial use (NonCommercial, or CC-BY-NC) provided the original author and source are credited.

\section{INTRODUCTION}

Anaemia in pregnancy remains one of the most intractable public health problems in the developing countries [1]. The World Health Organization (WHO) has estimated that more than half of the pregnant women in the world have a haemoglobin level $(<11.0$ $\mathrm{g} / \mathrm{dl}$ ) which is indicative of anaemia. The prevalence may however be more as seen in the developing countries [2]. Anaemia during pregnancy is associated with adverse infant outcomes, including low birth weight, preterm delivery and perinatal mortality, and it may also be associated with childhood intellectual disability. Women with even mild anaemia may experience fatigue and they may have a reduced work capacity. Severe anaemia is associated with maternal and child mortality [3]. Data from DLHS showed that prevalence of moderate and severe anaemia was high even among educated and higher income groups [4]. In India the National Nutritional Anaemia Control Programme (NNACP) was initiated in 1970 to provide free iron folic acid supplementation to pregnant women commencing from second trimester to three months postpartum. In a study, the Healthcare and Research Association for Adolescents and Nutrition Foundation of India, New Delhi, studied and concluded that prevalence and severity of anemia in rural pregnant women was $84 \%$, of which $9.2 \%$ were severe anaemia. The Indian Council Medical Research (ICMR)'s data also shows $84.2 \%$ anaemia prevalence in rural pregnant women, of which $13.1 \%$ were severe anaemia [5]. Successful management of anaemia in pregnancy depends on accurate and acceptable methods of detecting anaemia, assessing its severity and monitoring response to treatment [6]. Iron Deficiency Anaemia About $1000 \mathrm{mg}$ of iron is required during pregnancy, 500-600 mg for RBC expansion \& $300 \mathrm{mg}$ for foetus and placenta and the rest for the growing uterus. As a result of amenorrhea there is a saving of about $150 \mathrm{mg}$ of iron. As such $850 \mathrm{mg}$ of extra iron is required during pregnancy [7]. Diet alone cannot provide the extra iron 
and the stores which have around $500 \mathrm{mg}$ of iron get depleted. But if iron stores are already deficient, iron deficiency anaemia manifests. Iron deficiency anaemia (IDA) is the commonest type of anaemia in pregnancy [8] Because of physiological changes that occur during pregnancy, some of the haematological parameters, such as mean corpuscular volume (MCV), mean corpuscular haemoglobin $(\mathrm{MCH})$, and mean corpuscular haemoglobin concentration (MCHC), are not sensitive indicators for diagnosing anaemia / IDA because they are reduced only when anaemia is severe or well established [9]. Despite the fact that most of the anaemia's seen in pregnancy is largely preventable and easily treatable if detected in time, anaemia still continues to be a common cause of mortality and morbidity in India. Diminished intake and increased demands of iron, disturbed metabolism, pre pregnant health status and excess iron demands as in multiple pregnancies, women with rapidly recurring pregnancies, blood loss during labour, heavy menstrual blood flow, inflammation and infectious diseases are important factors which lead to development of anaemia during pregnancy $[10,11]$.

\section{AIMS \& OBJECTIVES}

- Estimate the prevalence of anaemia during delivery in primigravida.

- Clinically classify the severity of anaemia in different age groups.

- Comparison of prevalence with other parts of India

\section{MATERIAL \& METHODS}

The present study is a descriptive cross sectional observational study. Venous blood samples were drawn from pregnant women attending antenatal clinic for the assessment. EDTA tubes were used for adequate blood sample collection. Haemoglobin in grams, of 187 primigravida subjects who were admitted for delivery in Obstetrics and Gynaecology department of a tertiary teaching hospital in the rural area of Krishna District Andhra Pradesh were estimated by Lablife H3D Premier automated haematology analyser. The subjects were divided into three age groups, below 20 years, 20-25 years and more than 25 years for convenience. Anaemia was classified according to WHO criteria mild (9-11 gm \%), moderate (7-9 gm \%) and severe (4-7 gm \%). Women with twin pregnancies, bleeding disorders and multi gravida were excluded. The mean and standard deviations of haemoglobin in different age groups were calculated. The study was approved by Institutional Ethical Committee.

\section{Sample Size}

(A minimum sample size of 100 pregnant women would provide an estimate of prevalence with $+10 \%$ allowable error within $95 \%$ confidence limits, based on the knowledge that about $50 \%$ of the pregnant women in the country are anaemic).

\section{Data Analysis}

Data was entered and statistical analysis was performed using SPSS version 16, software. Descriptive statistics, including mean, and standard deviations, were calculated.

\section{OBSERVATIONS AND RESULTS}

The present study revealed that out of 187 primigavida pregnant women $91.1 \%$ below 20 years, $77.77 \%$ from $20-25$ years and $36.58 \%$ of more than 25 years were anaemic. Their mean $\mathrm{Hb}$ was $9.89 \mathrm{gms} / 100$ $\mathrm{ml}, 9.9$ gms / $100 \mathrm{ml}$ and $11.1 \mathrm{gms} / 100 \mathrm{ml}$ respectively. There were no cases of severe anaemia in all age groups and no cases of moderate anaemia in the age group above 25 years.

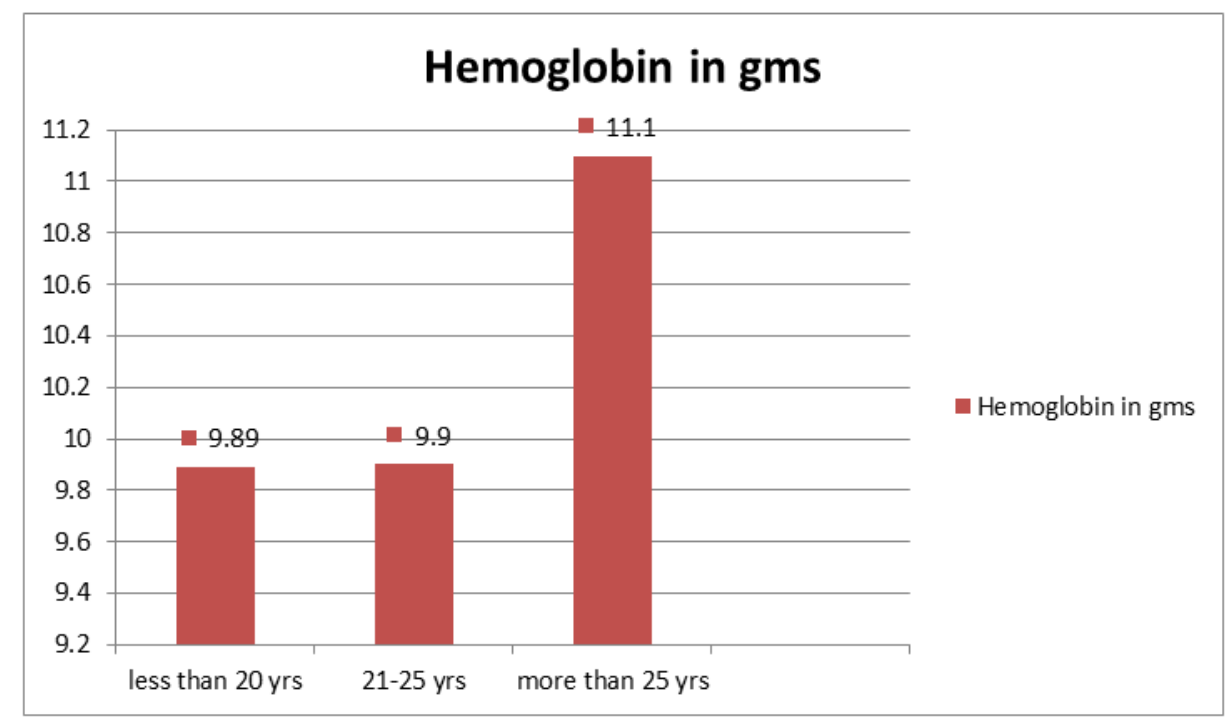

Fig-1: Average haemoglobin in different age groups in Primigravida pregnancy 
Table-1: Haemoglobin in grams in different age groups showing normal haemoglobin, mild and moderate anaemia

\begin{tabular}{|l|c|c|c|l|c|}
\hline \multirow{2}{*}{ AGE IN YEARS } & \multicolumn{3}{|c|}{ ANEMIA } & \multirow{2}{*}{ Total } \\
\cline { 2 - 5 } & MILD & MODERATE & SEVERE & NORMAL & Number(n) \\
\hline$\leq 20$ & $9.9 \pm 0.58(40)$ & $7.67 \pm 0.5(44)$ & 0 & $12.12 \pm 1.17(8)$ & 92 \\
\hline $20-25$ & $10.21 \pm 0.46(12)$ & $8.3 \pm 0.19(32)$ & 0 & $11.2 \pm 0.18(10)$ & 54 \\
\hline$\geq 25$ & $10.4 \pm 0.5(15)$ & 0 & 0 & $11.8 \pm 0.56(26)$ & 41 \\
\hline
\end{tabular}

\section{DISCUSSION}

This study confirmed that anemia is more common among primigravidae as recorded by Anorlu [12] and Nagaraj [13]. In a study by Lelissa D et al., in southern Ethiopia, the overall prevalence of anemia was $77 / 125(61.6 \%)$. In terms of severity, mild anemia was $41(53.2 \%)$, moderate anemia was $36(46.8 \%)$, and there was no severe anemia identified [14]. Mondal B et al., in West Bengal found that mean $\mathrm{Hb}$ level was $9.72 \mathrm{~g} / \mathrm{dl}( \pm 1.98)$. The mean $\mathrm{Hb}$ levels were slightly increased with the advancement of age correlating with our study [15]. The present study showed a proportional decrease in anemia with increasing age, contrary to the findings from the studies done in Maharashtra [16], Aurangabad [17], and Kashmir valley [18]. The prevalence of anemia was $67.6 \%$ among women aged less than 20 years at the time of pregnancy and significantly lower (57\%) for those women aged 31 and above at the time of pregnancy in a study by Jeetender Yadav [19].
Okunade K.S and Adegbesan-Omilabu found that anemia were more prevalent among primigravidae (33.9\%) than the multigravidae $(25.3 \%)$, although this difference was not statistically significant $(\mathrm{P}=0.079)$. The prevalence of anemia in primigravida in our study was $75.4 \%$ [20]. Viveki RG et al., found a high prevalence $(82.9 \%)$ of anemia (Haemoglobin < $11.0 \mathrm{gm} / \mathrm{dl}$ ) among 228 pregnant women. Majority $(50.4 \%)$ had moderate degree of anaemia (Haemoglobin - 7.0 to $10.0 \mathrm{gm} / \mathrm{dl}$ ) and $7.0 \%$ had severe anaemia (Haemoglobin - $7.0 \mathrm{gm} / \mathrm{dl}$ ) [17]. Chauhan stated primiparous group $(90.4 \%)$ were more anaemic than nulliparous (87\%) [21]. Haemoglobin levels were measured in 2950 pregnant women attending antenatal clinics in Kimpese, Bas Zaire. $72 \%$ were suffering from moderate anaemia (haemoglobin and $3.7 \%$ from severe anaemia at their first visit, before receiving any haematinics or anti-malarial prophylaxis [22].

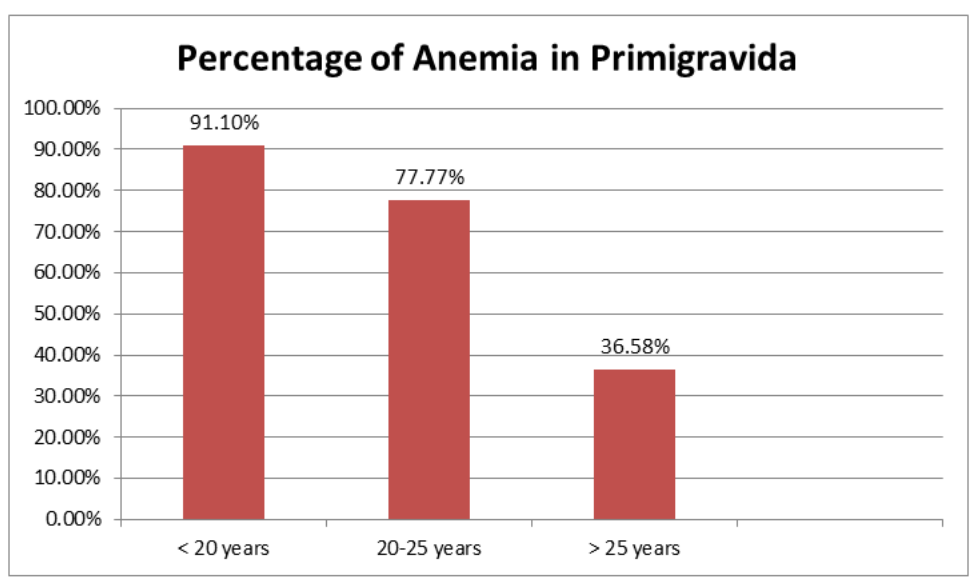

Fig-2: Age wise distribution of anemia

\section{CONCLUSION}

From our result we can conclude that anaemia is highly prevalent in rural area of Krishna district in primigravida. Our study revealed that the prevalence of anaemia is higher in younger age group in primigravida. The severity of anaemia decreased with age. Intervention including health education about causes of anaemia and its risk factors and regular antenatal follow-up should be given top priority.

\section{ACKNOWLEDGEMENTS}

We acknowledge Dr. G. Sajana, Professor and HOD, Dept of Obstetrics \& Gynaecology, Dr. Ranga Rao Diddi, HOD \& Professor, Department of
Pathology, Dr. Sajja Srikant, Professor\& HOD, Department of Physiology for their co-operation in this study.

\section{Source of Funding: Nil}

Conflicts of Interest: Nil

\section{REFERENCES}

1. Buseri FI, Uko EK, Jeremiah ZA, Usanga EA. Prevalence and risk factors of anaemia among pregnant women in Nigeria. The open hematology journal. 2008 Apr 7;2(1): 14-19.

2. The World Health Organization. Iron deficiency anaemia assessment, prevention and control. A 
guide for programme managers. Geneva, WHO/NHD/01, 2001.

3. Bentley ME, Griffiths PL. The burden of anemia among women in India. European journal of clinical nutrition. 2003 Jan;57(1):52-60.

4. DLHS on RCH. Nutritional status of children and prevalence of anaemia among children, adolescent grils and pregnant women, 2002-2004.

5. Indian Council of Medical Research. Evaluation of the National Nutritional Anaemia Prophylaxis Programme. An ICMR Task Force Study. New Delhi ICMR. 1989.

6. Prevention and management of severe anaemia in pregnancy. Geneva, World Health Organization, (unpublished document WHO/FHE/MSM/93.5; available upon request from Division of Reproductive Health, World Health Organization, 1211 Geneva 27, Switzerland). 1993.

7. Milman N, Bergholt $\mathrm{T}$, Byg KE, Eriksen L, Graudal N. Iron status and iron balance during pregnancy. A critical reappraisal of iron supplementation. Acta obstetricia et gynecologica Scandinavica. 1999 Jan 1;78(9):749-57.

8. Centers for disease Control, Criteria for anemia in children and childbearing aged women. MMWR, 1989; 38:400-404.

9. Rana S. Physiological changes and maternal adaptation to pregnancy, Obstetrics and perinatal care for developing countries. 5th ed. Aabpara Islamabad, Pakistan, 2002; 172-86

10. Toteja GS, Singh P, Dhillon BS, Saxena BN, Ahmed FU, Singh RP, Prakash B, Vijayaraghavan K, Singh Y, Rauf A, Sarma UC. Prevalence of anemia among pregnant women and adolescent girls in 16 districts of India. Food and Nutrition Bulletin. 2006 Dec;27(4):311-315.

11. Godkar PB, Godkar DP. Routine Haematological Tests. Textbook of Medical Laboratory Technology, 2nd Edition, Published by Bhalani Publishing House, Mumbai, India, 2003; 738-742.

12. Anorlu RI, Oluwole AA, Abudu OO. Sociodemographic factors in anaemia in pregnancy at booking in Lagos, Nigeria. Journal of Obstetrics and Gynaecology. 2006 Jan 1;26(8):773-776.

13. Nagaraj K. Risk Factors Of Severe Anaemia Among Pregnat Women Attending a Government Maternity Hospital in Tirupati, India-A
Multivariate Analysis. Journal of Human Ecology. 2003 Jul 1;14(4):237-240.

14. Lelissa D, Yilma M, Shewalem W, Abraha A, Worku M, Ambachew H, Birhaneselassie M. Prevalence of Anemia Among Women Receiving Antenatal Care at Boditii Health Center, Southern Ethiopia. Clinical Medicine Research, 2015; 4(3), 79-86.

15. Mondal B, Maiti S, MaitY B, Ghosh D, Paul S. Prevalence of anaemia among pregnant Bauri women of Bankura, West Bengal, India. Journal of Clinical and Diagnostic Research. 2012 Apr;6(2):231-233.

16. Ahmad N, Kalakoti P, Bano R, Syed MMA. The prevalence of anaemia and associated factors in pregnant women in a rural Indian community. Australas Medical Journal, 2010; 3(5): 276-280.

17. Viveki RG, Halappanavar AB, Viveki PR, Halki SB, Maled VS, Deshpande PS. Prevalence of anaemia and its epidemiological determinants in pregnant women. Al Ameen $\mathrm{J}$ Med Sci. 2012;5(3):216-223.

18. Rauf-ur-Rashid Kaul JA, Baba T, Shoib S, Ahmad A, Ashraf M, Ahmad R. Anaemia in pregnant women in a rural block of Kashmir valley: its prevalence and socio-demographic associates. International Journal of Medical Science and Public Health. 2013;2(4): 814-818.

19. Yadav J. Prevalence and Factor Associated with Maternal Anaemia in India: Analysis of A Nationally Representa-tive Cross-Sectional Survey, 2012-13. BAOJ Hematol. 2017;1(002).

20. Okunade KS, Adegbesan-Omilabu MA. Anaemia among pregnant women at the booking clinic of a teaching hospital in south-western Nigeria. International Journal of Medicine and Biomedical Research. 2014;3(2):114-20.

21. Chauhan AS, Sharma MK, Chauhan HS. Anaemia and its associated factors among pregnant women in rural area of North India. The New Indian Journal of OBGYN. 2017, July-December; 4(1)

22. Jackson DJ, Klee EB, Green SD, Mokili JL, Elton RA, Cutting WA. Severe anaemia in pregnancy: a problem of primigravidae in rural Zaire. Transactions of the Royal Society of tropical Medicine and Hygiene. 1991 Nov 1;85(6):829832. 